\title{
Vibration and Cylinder Chamber Pressure Characteristics of an Air Reciprocating Compressor
}

\author{
Bambang Daryanto Wonoyudo ${ }^{1}$ and David A. Siregar ${ }^{2}$
}

\begin{abstract}
In the application of a reciprocating compressor failures are often caused by valve malfunction. The failure can be minimized by a proper valve design. This research described an experimental study to investigate characteristics of vibration and cylinder chamber pressure diagrams, as results of open-close valve processes in a single-stage, single-acting air reciprocating compressor. Vibration and pressure were measured at the same crank angle. The modification was materialized by a change in a valve seat profile of a discharge side. The study was conducted for several working loads. Compared to the discharge valve which was (commonly) supplied by the manufacturer, the result showed that a provision of a taper angle on a discharge valve seat would decrease vibration level, made longer discharge opening, and would increase discharge pressure.
\end{abstract}

Keywords - reciprocating compressor, valve seat, vibration, pressure.

\section{INTRODUCTION}

$\mathrm{A}^{\mathrm{i}}$ ir reciprocating compressors are widely used in light industries, either as auxiliary equipment or as main units. It is in the best interest that air reciprocating compressors are in good operating conditions and reliable. A survey conducted by a company which manufactured a lot of air compressors showed that failures of reciprocating compressor were often caused by valve malfunction [1]. It is therefore a compressor valve has become a subject of many researches: experimentally or analytically, theoretically or practically, research or trouble shooting. A proper design of a valve would enhance compressor's dependable performance [2]. Until recently a valve design has been a focus of development studies [3, 4], in order to improve compressor performance.

An increase in compressor reliability due to valve designs on a gas industry was shown by Brun et al. [5]. Another study of valve design on an oil, gas and petrochemical industry was presented by Wilson [6]. While experimental study with interest on the effect of different coolant was conducted by Pipalia, Thummar, and Javiya [7]. Heidari et al. [8] used an energetic microscopic representation for a dynamic nonlinear modeling to enhance performance of a reciprocating air compressor. And, Brun and Nored [9] described experimental and analytical results to predict valve life and performance, using finite element calculation together with material fatigue testing and optical valve plate measurements. A study on compressor performance analysis of small discharge and suction ports due to leakage on piston rings and valves was conducted by Diab and Howard [10]. On-line monitoring was reported by Schirmer, Fernandes and De Chaux [11], where measurement data were displayed in $\mathrm{P}-\mathrm{V}$ diagram that became a basis for a compressor performance analysis.

Erol and Gurdogan [12] conducted a research on vibration and noise characteristics of an inter-mediate

${ }^{1}$ Bambang Daryanto is with Departement of Mechanical Engineering, Faculty of Industrial Engineering, Institut Teknologi Sepuluh Nopember, Surabaya, 60111, Indonesia. E-mail: bambang@me.its.ac.id.

${ }^{2}$ David A. Siregar is with Theiss Contractor Indonesia, Balikpapan, Indonesia. E-mail: dsiregar@theiss.co.id plate of a discharge port of a reciprocating compressor. Vibration measurements and criteria could be seen on EFRC Guidelines [13], and the cylinder chamber pressure was given in [14].

\section{DESCRIPTION OF WORK}

The investigation is basically an experimental study on the effects of the change of a discharge valve seat (from a profile that is provided by the OEM) on the vibration and cylinder chamber pressure characteristics of a singlestage, single-acting air reciprocating compressor. The study is conducted in several working pressures.

The aim of the study is to know the effects in vibration and cylinder chamber pressures when there is a change of the geometry of a discharge valve seat. The results are intended to become a reference for those who are interested designing a valve seat profile, in order to increase durability and performance of a reciprocating compressor. The air reciprocating compressor with an unmodified discharge valve seat becomes a baseline to which results of modified valve seats to be compared. The discharge port is chosen because the high pressure happens in a discharge stage (compared to a suction step).

\section{RESULT AND DISCUSSION}

\section{A. Reciprocating Compressor Cycle}

The understanding of a reciprocating compressor can be started from a P-V diagram. In Figure 1, horizontal direction illustrates a fluid volume and a vertical direction illustrates a pressure, in one cycle of a reciprocating compressor. An actual P-V diagram of a reciprocating compressor is shown in Figure 1, where an ideal reciprocating compressor $\mathrm{P}-\mathrm{V}$ diagram is without losses. Areas above and below an A-B-D-E curve indicate power which are needed to activate valves and to overcome resistances in dealing with opening and closing both discharge and suction valve. The above diagram can be converted into P- $\theta$ diagram, where a horizontal axis indicates a crank angle and a vertical axis indicates a pressure, as shown in Figure 2.

A-B curve illustrates an expansion step of a reciprocating compressor, where air volume expands and its pressure drops. In B-C curve air has negative pressure 
(below the line of suction pressure), as a result of downward piston movement until the piston reaches bottom dead center. When the piston reaches BDC, the pressure meets the line of suction pressure, where the suction port is closed. In C-D curve the piston moves from BDC to top dead center. The compression stage happens, and air pressure increases. Actually point D is above the line of discharge pressure. The discharge port opens from point $\mathrm{D}$ until air pressure reaches the line of discharge pressure (point $\mathrm{E}$ or A). And the cycle repeats itself.

\section{B. Vibration}

Machinery which has moving parts will yield a mechanical motion when it operates. This mechanical motion will produce vibration in the machine. A particular vibration level will induce or indicate a failure in one or more than one parts of machinery. Vibration varies with location; therefore each location can have a different vibration profile. Commonly, for the purpose of analysis, vibration monitoring is conducted only in certain points.

The working principle of a transducer is to capture a vibration signal and convert it into an electrical signal, and then send a signal to a data logger. Based on the kept data, vibration visualization can be done to make further analysis. Amplitude is the main indicator for assessing the condition of machinery.

Vibration which happens on reciprocating compressor takes place because of an excitation force that appears. This excitation force is caused by variation of a cylinder chamber pressure and imbalance due to the crankshaft operation. Vibration is mainly caused by open-close processes of valves. The open-close motions of valves generate impacts on valve seats and valve heads. The ensuing impacts are put through the compressor body and materialized as vibration.

Significant amplitudes are commonly caused by four happenings: discharge valve open, discharge valve close, suction valve open, suction valve close.

\section{Valve Component}

The studied valve is a flat plate type, shown in Figure 3. The valve consists of four main components: valve seat, stop plate (guard), valve plate (sealing), spring. Schematically, Figure 4 shows a discharge valve seat as supplied by the vendor (manufacturer). The discharge valve seat as supplied by the vendor is called the valve seat with normal (unmodified) profile.

\section{METHOD}

Acquired data for this study are from an air reciprocating compressor, with the following specification:
a. Type
b. Speed
c. Power
d. Drive

e. Working pressure

f. Speed reduction

: single stage, single acting

: $630 \mathrm{rpm}$

: $2 \mathrm{HP}$

: electrical motor 380 volt, $1430 \mathrm{rpm}$

: $7 \mathrm{~kg} / \mathrm{cm} 2$

: belt transmission

The two variables being measured are vibration acceleration of a cylinder head and a pressure of a cylinder chamber. Both variables are taken simultaneously, and then are plotted against a crank angle. Measurement at the same time is triggered by used of a tachometer. Measurement data are recorded by a data logger, which in turn are downloaded to a digital computer, so that cylinder chamber pressure and vibration graphs can be displayed. Varied working pressures are conducted to verify the effects of modified valve seat profiles.

On the outer side of a cylinder head is placed an accelerometer equipped with a magnetic base to measure the ensuing vibration. A hole is drilled in the cylinder head to place a pressure transducer, so that a chamber pressure can be measured. The vibration and the cylinder chamber pressure are measured at the same time, i.e. both signals are measured at the corresponding crank angle. Data are taken for different discharge valve seat designs, as shown by Figure 7. Each design is applied on the compressor, in order to know its effect on the compressor.

\section{RESULT AND ANALYSIS}

\section{A. Vibration and Pressure of Normal Valve}

A normal valve seat is meant a valve seat design or geometry as supplied by OEM without design modification. As a typical example, Figure 8 illustrates a vibration pattern and a $\mathrm{P}-\theta$ diagram of a discharge normal (unmodified) valve seat, for working pressure of 3 bars. The following figures (Figure 9 and 10) show vibration pattern and a $\mathrm{P}-\theta$ diagram of the unmodified valve, for working pressure of 2 bars to 6 bars.

B. Vibration and Pressure of Modified Valve

As typical examples, the following figures show vibration pattern (measured at the outside of the cylinder head) of a modified valve seat geometry with a 300 and 400 conical angle, and the depth of the hole of $1 / 2 \mathrm{t}(\mathrm{t}$ : thickness of valve seat $=8 \mathrm{~mm})$. P- $\theta$ diagrams are represented by a diagram of $30^{\circ}$ and $40^{\circ}, 1 / 2$ t (Figure 13).

The difference from a normal one is that the modified discharge valve seat has a central torus hole of different depth $(1 / 4 \mathrm{t}, 1 / 2 \mathrm{t}, 3 / 4 \mathrm{t})$, as shown in Figure 7 .

A chamfer on a discharge valve hole brings a better fluid flow characteristic. From a vibration waveform graphic can be seen that there is improve of vibration level of the modified discharge valve seat from the normal one, that (may be) because of smoothing in the flow, as a result of the given chamfer on the discharge valve seat. The central torus hole of the modified valve seat will reduce whirl of working fluid flow, where the whirl may disturb an opening-closing of valves.

In general, from a P- $\theta$ graphic, a central torus hole of a discharge valve seat (compared to the unmodified one) brings the effect of the opening of a discharge valve happens earlier, while the closing of a discharge valve happens later. Hence, the time interval of the opening of a discharge valve becomes longer. The effect of central torus hole of a discharge valve seat is not significant on the opening-closing of a suction valve.

Compared to the unmodified one, the modified discharge valve seat increases the discharge pressure. This implies that the opening of a discharge valve happens earlier.

Generally speaking, compared to the discharge valve seat as supplied by the OEM, the present of a central torus hole makes the vibration level lower and increases a discharge pressure. 


\section{CONCLUSION}

Analyses on the vibration and pressure signals of modified discharge valve seat profiles of an air reciprocating compressor bring several findings, as follows:

1. With chamfer on central hole of a discharge valve seat, a better vibration pattern occurs.

2. With chamfer on central hole of a discharge valve seat, time interval of discharge valve opening is longer, mainly because of discharge valve opening which happens earlier (compared to unmodified one).

3. With chamfer on central hole of a discharge valve seat, generally the increase of a discharge pressure takes place.

\section{ACKNOWLEDGEMENT}

Equipment and facilities provided by the Department of Mechanical Engineering ITS, are acknowledged.

\section{REFERENCES}

[1]. S. Foreman, "Compressor Valves and Unloaders for Reciprocating Compressors", technical report, Dresser-Rand, New York, 19 pages, 2002.

[2]. D. Woollatt, "Reciprocating Compressor Valve Design: Optimizing Valve Life and Reliability", Dresser-Rand, New York, www.dresser-rand.com, 2003.

[3]. J. Jin, G. Sui and D. Shen, "Research of Dynamic Performance of Reciprocating Compressor Valve", Advanced Materials Research, pp. 1198-1202, 2013.

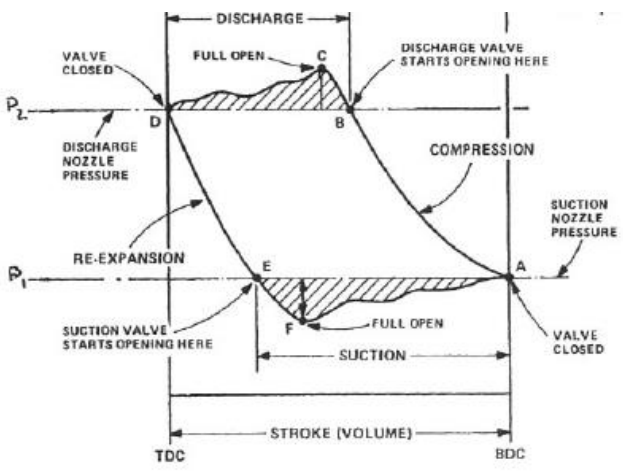

Figure 1. P-V Diagram of Reciprocating Compressor

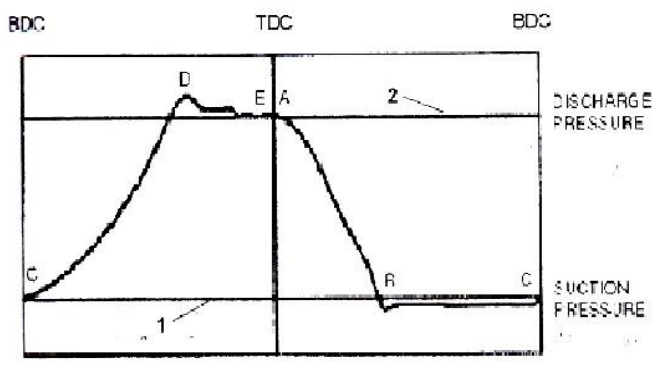

Figure 2. P- $\theta$ Diagram of Reciprocating Compressor
[4]. A. Bhakta, S. Dhar, V. Bahadur, S. Angadi and S. Dey, "A Valve Design Methodology for Improved Reciprocating Compressor Performance", Intl. Compressor Engineering Conference, Purdue Univ., West Lafayette, IN, 8 pages, 2012.

[5]. K. Brun, R.S. Gernentz, M.O. Smolik and J.P. Platt Jr., "SemiActive Compressor Valve Development and Testing", Pipeline \& Gas Journal, pp. 40-42, 2006.

[6]. R.S. Wilson, "Compressor Optimization", paper presented at CO Conference, Aberdeen, Scotland, 2007.

[7]. V.F. Pipalia, A. Thummar and T. Javiya, "Experimental Investigation of Overall Efficiency of Two-Stage Reciprocating Air Compressor by way of Intercooling”, Intl. J. Advanced Research in Science Engineering and Technology, pp. 09-14, 2012.

[8]. M. Heidari, M. Tsirinomeney, A. Rufer and P. Barrade, "Modeling of an Air Compressor Using Energetic Microscopic Representation", Intl. Compressor Engineering Conference, Purdue Univ., West Lafayette, IN, 10 pages, 2012.

[9]. K. Brun and M. Nored, "Valve Performance and Life of Reciprocating Compressors, Proc. 41 ${ }^{\text {st. }}$ Turbomachinery Symposium, Houston, TX, 12 pages, 2012.

[10]. S. Diab and B. Howard, "Reciprocating Compressors Management Systems Provide Solid Return on Investment", technical paper, GE Energy, 2005.

[11]. A.G.F. Schirmer, N.F. Fernandes and J.E. De Chaux, "On-line Monitoring of Reciprocating Compressors", paper presented at NPRA Maintenance Conference, San Antonio, TX, 2004.

[12]. H. Erol and A. Gurdogan "The Noise and Vibration Characteristics of a Reciprocating Compressor: Effects of Size and Profile of Discharge Port", Proc. $15^{\text {th }}$ Intl. Compressor Engineering Conference, Purdue Univ., West Lafayette, IN, pp. 677-683, 2000.

[13]. EFRC, "Guidelines for Vibration in Reciprocating Compressor Systems", 30 pages, 2009.

[14]. P.C. Hanlon, editor, "Compressor Handbook", McGraw-Hill, New York, 2001.

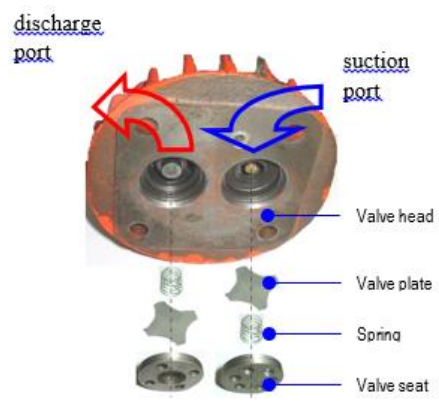

(a)

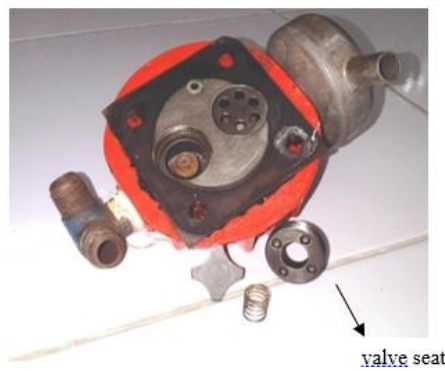

(b)

Figure 3. Valve Component 


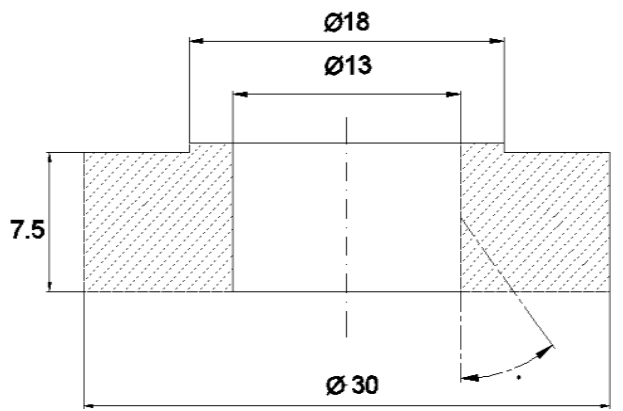

Figure 4. Normal Valve Seat

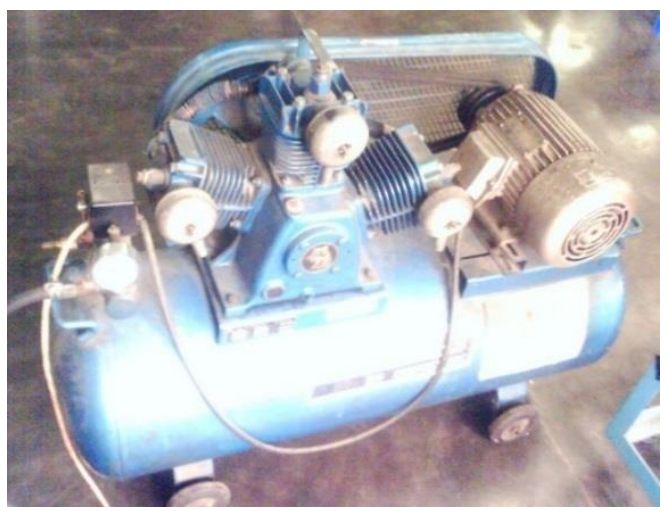

Figure 5. Air Reciprocating Compressor

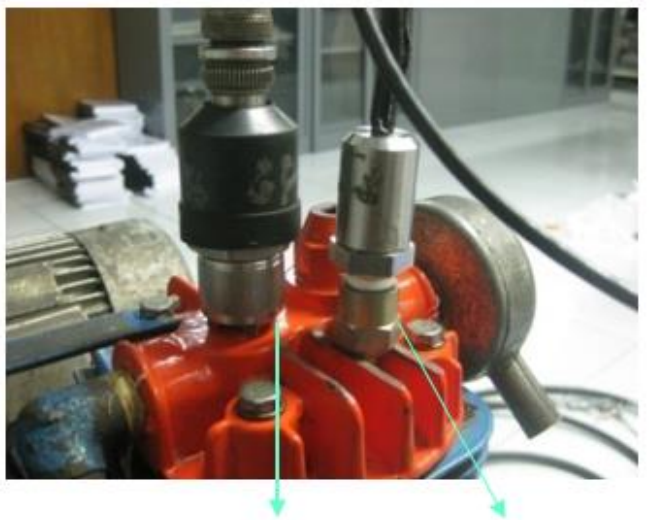

accelerometer pressure transducer Figure 6. Sensors on Cylinder Head
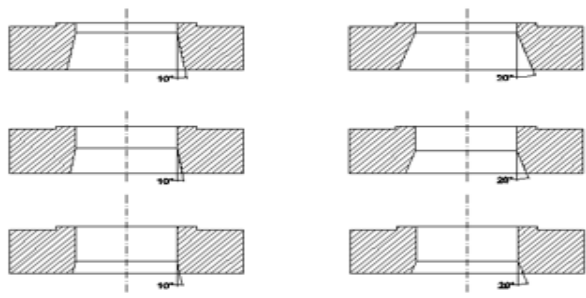

A
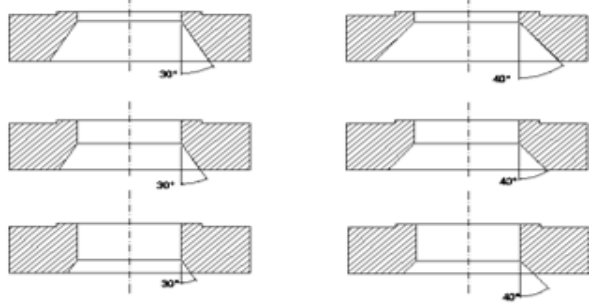

D

Figure 7. Modified Valve Seat Profile A : conical angle $10 \mathrm{O}, 1 / 4 \mathrm{t}, 1 / 2 \mathrm{t}, 3 / 4 \mathrm{t}$

B : conical angle $20 \mathrm{O}, 1 / 4 \mathrm{t}, 1 / 2 \mathrm{t}, 3 / 4 \mathrm{t}$

C : conical angle $30 \mathrm{O}, 1 / 4 \mathrm{t}, 1 / 2 \mathrm{t}, 3 / 4 \mathrm{t}$

D : conical angle $40 \mathrm{O}, 1 / 4 \mathrm{t}, 1 / 2 \mathrm{t}, 3 / 4 \mathrm{t}$

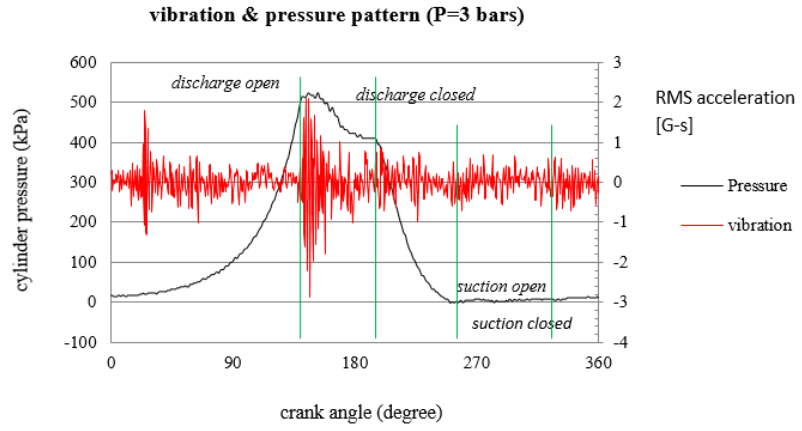

Figure 8. Waveform and Pressure of Unmodified Valve

$\begin{array}{lll} & \text { LMF }- \text { Comp Re } \\ \text { CPV } \quad-\text { PTS }=\text { CV2 CV3 } & 4 \text { CV5 CVG }\end{array}$

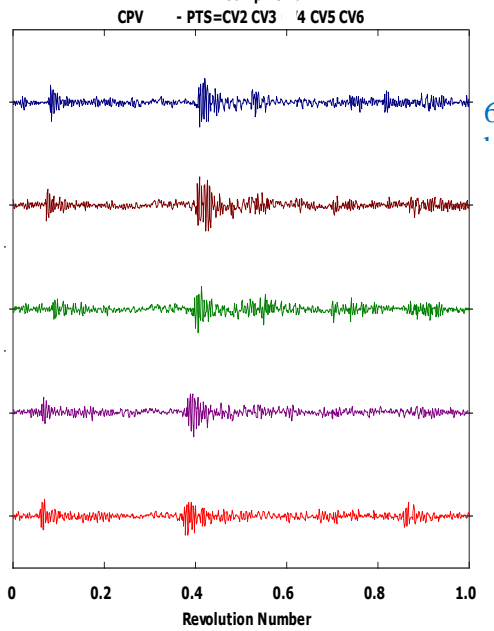

Figure 9. Waveform of Unmodified Valve, 2 to 6 bars

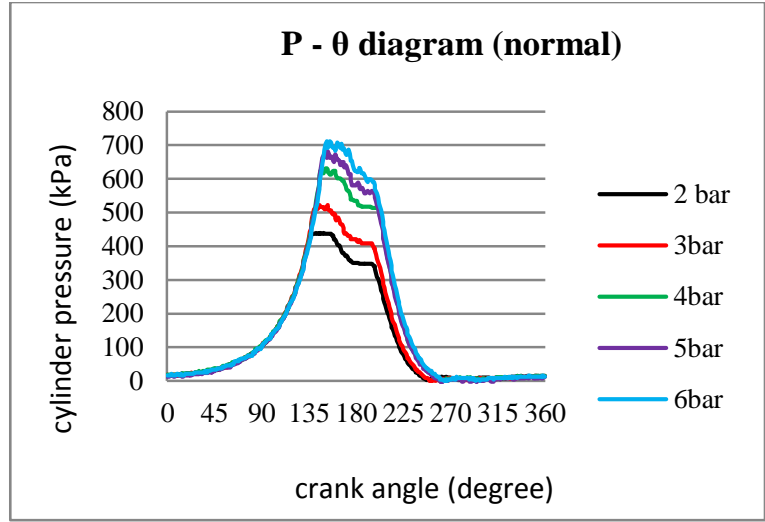

Figure 10. Pressure vs. Crank Angle of Unmodified Valve, 2 to 6 bars

$\begin{array}{lll}\text { LMF }- \text { Comp RE } & \text { P } \\ \text { CPV } & -P T S=C V 1 \text { CV2 } & 13 \text { CV4 CV }\end{array}$

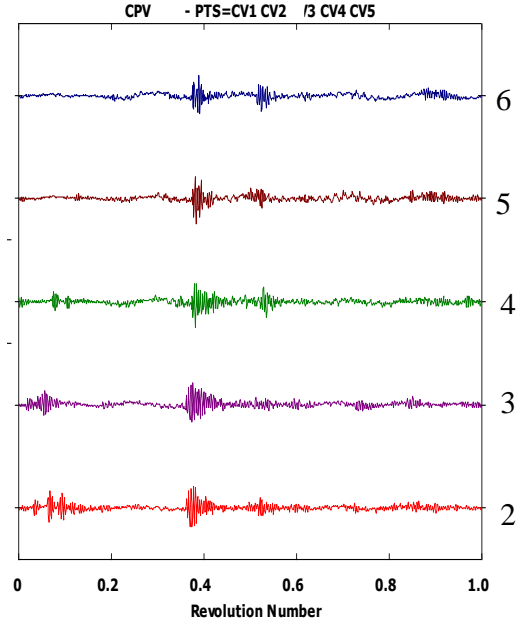

Figure 11. Waveform of Modified Valve, torus angle $30^{\circ}, 1 / 2 t$ 


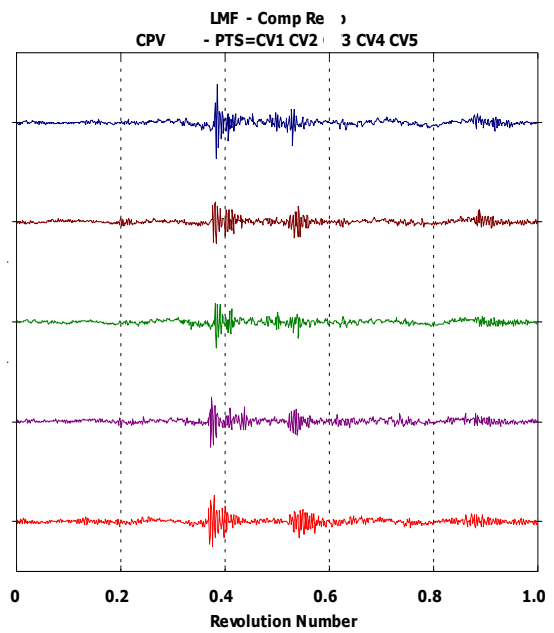

Figure 12. Waveform of Modified Valve, torus angle $40^{\circ}, 1 / 2 \mathrm{t}$

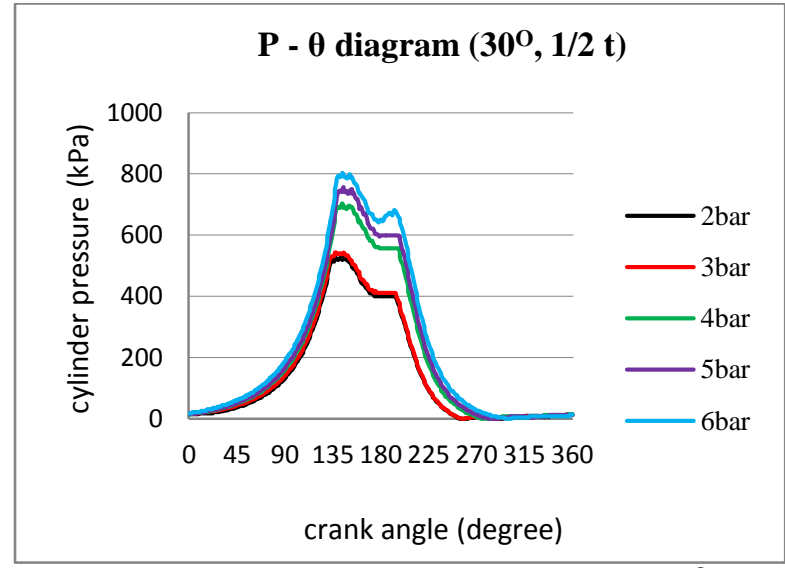

Figure 13. P- $\theta$ Diagram of Modified Valve, torus angle $30^{\circ}, 1 / 2 \mathrm{t}$

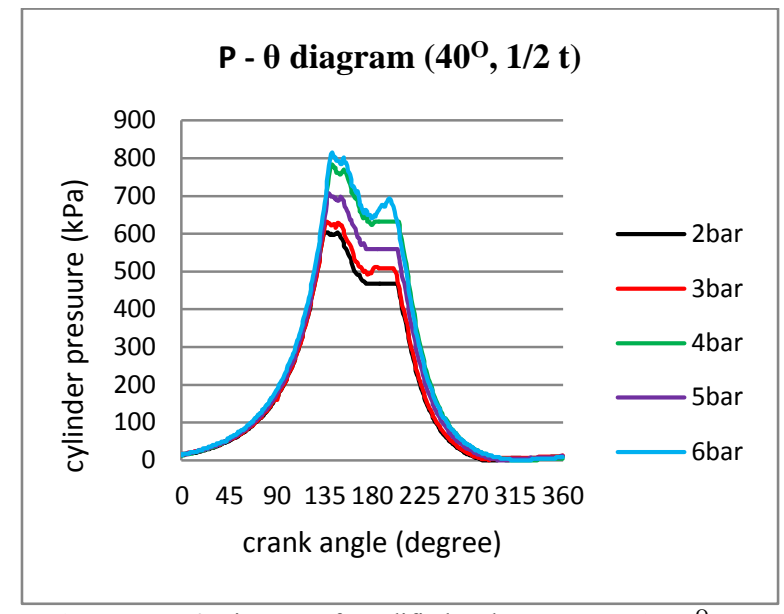

Figure 14. P- $\theta$ Diagram of Modified Valve, torus angle $40^{\circ}, 1 / 2 \mathrm{t}$ 